\title{
O empoderamento dos pais na educação e nos cuidados dos filhos: contribuições teóricas
}

\author{
Empowerment of parents in education and care of children: \\ psychoanalytic contributions
}

\begin{abstract}
Sérgio Murilo Ferreira, ${ }^{1}$ Flávia Cristina Busch Boregas, ${ }^{1}$ Bruna Rafaele Milhorini Greinert, ${ }^{1}$ Diógenes Aparício Garcia Cortez, ${ }^{1}$ Rute Grossi Milani ${ }^{1}$

'Centro Universitário Cesumar, Programa de Pós-Graduação em Promoção da Saúde, Maringá, PR, Brasil.
\end{abstract}

Recebido em: 29/07/2016 / Aceito em: 02/09/2016 / Publicado em: 30/09/2016

srgmuriloferreira3@gmail.com

\section{RESUMO}

O termo empoderamento remete a uma gama de ações, é um termo plurifacetado, processo dinâmico. $\mathrm{O}$ empoderamento dos pais ocorre quando estes se percebem como detentores de recursos para educar e exercer suas funções de proteção e promoção ao desenvolvimento saudável dos filhos, porém a tarefa de educar é complexa e requer aprendizado, envolve desafios que podem conduzir a práticas pouco eficazes. Objetivo: compreender o processo de empoderamento dos pais na educação e nos cuidados dos filhos. Método: o estudo foi realizado com base em revisão bibliográfica realizada por meio de buscas eletrônicas nos bancos de dados Scientific Electronic Library Online (SCIELO), Pepsic e em livros especializados, visando verificar as contribuições teóricas, principalmente as psicanalíticas, sobre o tema. Resutados: foi possível constatar a existência de uma relação entre educação e saúde, especialmente no que tange aos cuidados iniciais e desenvolvimentais destinados às crianças, oriundos dos pais ou cuidadores. Considerações Finais: o empoderamento nos cuidados dos filhos, nos processos educacionais, disciplinares e vinculares possibilita a promoção da saúde ao desenvolver aspectos relativos à empatia, autoestima, consciência moral e ética. A criança necessita e busca em seus pais parâmetros norteadores representativos de leis, normas e, consequentemente, referências.

Palavras-chave: Empoderamento; Vinculação Familiar; Psicanálise; Promoção da saúde.

\section{ABSTRACT}

The term empowerment refers to a range of actions; it is a multifaceted term, a dynamic process and adds many contexts, among them: school, clinical, social, family and health. When we talk about education and care, especially in childhood, a wide network of meaning soon come to mind; representations and concepts related to individual power and collective power with and in relation to, simultaneous development and not hierarchical, to promote and encourage groups or communities. Parental empowerment occurs when parents realize how resource holders to educate and perform their protective functions and how best to promote the healthy development of children. But the task of educating is complex and requires learning; it involves challenges that can lead to inefficient practices. Objective: to understand the process of empowerment of parents in the education and care of children. Method: based on a literary review via electronic searches in publications in the Scientific Electronic Library Online (SciELO) databases, as well as in specialized books, in order to verify the theoretical contributions, especially psychoanalytic, on the subject. Results: it was possible to verify that the family institution is a reference in representation and responsibility in the transmission of aspects of education and care. Closing Remarks: the child needs and searches for their parents' representative guiding parameters of laws, rules and consequently references. For psychoanalysis, any connection between the subject and the external world means emotional investment, so the results of psychoanalytic research are of great importance to education, resulting in effective processes and primacy in psychic life.

Keywords: Empowerment; Linking the Family Context; Psychoanalysis; Health promotion. 


\section{INTRODUÇÃO}

Empoderamento é um termo plurifacetado, um processo dinâmico que incorpora aspectos cognitivos, afetivos e condutuais, possui também uma conotação política emancipatória. Introduzido pela primeira vez na década de setenta, rapidamente tornou-se de uso corrente, sobretudo entre movimentos de caráter social.

O empoderamento ocorre quando os indivíduos estão conscientes da realidade em que vivem, bem como dos recursos que lhes permitem influir e/ou controlar tal realidade. É um conceito polissêmico que engloba ações de impulso a grupos e comunidades vulneráveis, nos quais se busca a efetiva melhora de suas existências, com autonomia e qualidade de vida. ${ }^{1}$ A terminologia encontra-se relacionada à potência individual e coletiva, associada ao desenvolvimento simultâneo e não hierárquico, visando promover e impulsionar grupos ou comunidades. ${ }^{2}$

Os pais na contemporaneidade se deparam com conflitos diversos na educação dos filhos, demonstram embaraços em práticas cotidianas simples como o estabelecimento de limites de horário para dormir, para a realização de refeições e aplicação de rotinas diárias. Vive-se a ausência de padrões pelas quais orientar os pensamentos e condutas, uma crise de valores em que o certo e o errado, o bonito e feio, o verdadeiro e o falso misturam-se, sendo considerados meras questões de opinião. ${ }^{3}$

O ser humano depende de significações, isto é, do valor que tem para o outro. Portanto, a criança busca em suas figuras representativas iniciais, os pais, seus primeiros significantes, visando obter amparo e condições para constituir seu próprio modo de ser e se relacionar com o mundo. ${ }^{4}$ Percebe-se que o exemplo dos pais tem relevância na assimilação de normas por parte dos filhos, o que dá legitimidade e representação eficiente ao diálogo para o estabelecimento de regras. ${ }^{5}$

A sociedade atual vivencia um momento de intensos debates e discussões a respeito das funções parentais e das configurações familiares. Os novos modelos de relações familiares estão associados ao declínio da função parental, pois nota-se o enfraquecimento da autoridade paterna e as dificuldades que as mães apresentam, em exercerem a função materna. ${ }^{4}$ Uma vez que a criança é fruto do desejo dos próprios pais, é necessário questionar a família em relação às suas responsabilidades como entidade primária para a formação de um novo ser, na tentativa de reconduzi-la a seu papel como promotora do desenvolvimento saudável da criança.

A criança só se tornou sujeito de direitos no século $X X$, pela ONU, nessa época pesquisadores se propuseram a entender melhor o desenvolvimento infantil, o que propiciou o surgimento de debates sobre a prática das punições corporais utilizadas até os dias atuais. A punição corporal sempre esteve aliada à disciplina, mas só o uso da disciplina estabelecida com regras, limites consistentes e lógicos e com supervisão sistemática de um adulto, pode promover a autonomia da criança e o fortalecimento de sua autoestima. Filhos que possuem vínculos afetivos reforçados tendem a investir energia na manutenção destes e são estimulados a dedicar, continuamente, estes esforços no estabelecimento de um ambiente propício ao diálogo. ${ }^{6}$

A correlação entre uma maior participação dos pais na vida da criança, num modelo de participação mais construtivo e a aquisição de habilidades por esta, torna-se cada vez mais evidente, apontando a importância de uma relação que priorize o diálogo e a orientação. Os pais devem confiar no potencial de seus filhos para compreenderem a importância de regras, visando à construção de uma relação construtiva e harmoniosa. ${ }^{7}$

É consenso na literatura, a necessidade de problematização da educação dos jovens e infantis, portanto, a proposta deste artigo decorre da necessidade de apontamentos e contribuições que auxiliem os pais e cuidadores no processo de empoderamento. Voltaremos nosso olhar às dimensões afetivas, utilizando os referenciais e contribuições psicanalíticos na compreensão e articulação do fenômeno moral como um todo, visando à compreensão do processo de empoderamento parental, na educação e cuidado dos filhos.

A psicanálise enquanto prática de subjetivação e não de normalização dos sujeitos, edificou inéditos campos potenciais para a clínica, campos, estes, que vêm ultrapassando fronteiras e limites instituídos anteriormente, entrando no campo social, como um construto teórico com aplicabilidade cabível a diferentes áreas do conhecimento, como a literatura e a educação. ${ }^{8,9}$ As formulações teóricas introdutórias concernentes à psicanálise de crianças começaram a tomar forma por intermédio dos trabalhos inovadores de Melanie Klein e Anna Freud, o que contribuiu com a inserção da psicanálise no Brasil. Tais estudos influenciaram as práticas dedicadas ao cuidado da criança, tanto no âmbito da saúde, como elemento complementar no tratamento de crianças com problemas emocionais, quanto no da educação, com o intuito de promoção da saúde mental da criança. ${ }^{9}$

Nesse contexto, este estudo objetiva compreender, mediante uma revisão narrativa da literatura, o processo de empoderamento dos pais na educação e cuidados dos filhos, considerando as contribuições teóricas, principalmente as psicanalíticas, que reivindicam, para os processos afetivos, a primazia na vida psíquica.

\section{MÉTODO}

Para tanto, fez-se uma revisão bibliográfica por meio de buscas eletrônicas, nas bases de dados Scientific Electronic Library Online (SCIELO) e Pepsic, bem como em livros especializados. Os resultados foram organizados em duas categorias principais: o empoderamento dos pais sob a construção moral e o empoderamento dos pais sob a estruturação relacional vincular, as quais serão apresentadas a seguir.

\section{RESULTADO}

\section{Empoderamento dos pais sob a construção moral}

A determinação de limites faz parte da educação e do processo civilizador e, portanto, a ausência total dessa prática pode gerar uma crise de valores, um retrocesso a um estado selvagem em que vale a lei do mais forte, de modo que, não existe civilização sem repressão, sem sérias restrições e sem limites. ${ }^{3}$

No Brasil, a área da Psicologia Moral foi desen- 
volvida na década de 1990, voltada a compreender o modo como os processos mentais podem associar-se a regras, princípios e valores morais. ${ }^{10}$ Yves de La Taille descreve quatro abordagens representativas da psicologia moral, duas relativas às dimensões afetivas dos comportamentos morais, citando Émile Durkhein (1902/1974) e Sigmund Freud (1929/1971) e duas com enfoques racionais construtivistas, que valorizam a razão e a autonomia, no caso Jean Piaget (1932) e Lawrence Kholberg (1981). ${ }^{11}$

Durkhein (1902/1974) contribuiu com a visão de formação moral, visando relacionar, em crianças, o sentimento de sagrado à sociedade, o que resultaria em respeito devido às normas morais. Freud (1929/1971) destacou o caráter conflitivo relacional do indivíduo com a moral, realçando que a consciência moral possui raízes inconscientes, de tal modo que a ação moral pode ser entendida por um movimento de forças afetivas e sentimentos vivenciados pela criança em relação às figuras parentais. ${ }^{11}$

Há três significados para limites, inicialmente as sociados a um preposto para se atingir a maturidade, ou se alcançar excelência, transitando para o que deve ser respeitado e não transposto, finalizando com a linha de intimidade entre o eu e o outro, especificamente no que cerne ao espaço de acesso nesta relação. Os três sentidos são complementares entre si. ${ }^{11}$

Nessa ótica, deve-se caminhar entre a tênue linha da omissão e da intromissão. Ressalta-se a existência, na atualidade, de adultos com dificuldades em assumir papeis representacionais de adulto, de pai, de cuidador, de educador e é equivocada a delegação de responsabilidades a crianças ou jovens, sem avaliar previamente as condições que estes apresentam para assumir de fato tais responsabilidades. Assim como, a tentativa impostora de subjetividade, infligindo o sofrimento alheio, visto ser um erro julgar dentro do direito de normatizar, não só a conduta do outro, mas também seus afetos. ${ }^{11}$

Os pais precisam nortear estratégias educativas para que os filhos internalizem suas normas de modo responsável, mesmo quando não houver representantes de indicadores normativos. Para tanto, cuidadores precisam estabelecer laços afetivos, de consideração e respeito, possibilitando que a criança internalize normas disciplinares. É preciso que a criança tenha limites claros, simples e fáceis de serem entendidos, além de justos, coerentes, e com consequência caso não cumpridos, para que atinja um comportamento responsável, pois os limites devem permitir que a criança desenvolva uma capacidade de escolha amparada na representação disciplinar. ${ }^{12}$

O caminho para o amadurecimento infantil vem da inquietação e desestabilização parental; orientar a criança no caminho do conflito a conduz na busca de conhecimento, ou moral superior, que substitui o seu conhecimento infantil anterior. $\mathrm{O}$ excesso de mimos e elogios sobrecarrega a criança com a responsabilidade de ser sempre a melhor, bem como, socorrê-la demasiadamente em seus erros, mesmo quando ela poderia assumir a responsabilidade, priva-lhe de ter a compreensão do que é ser responsável. Portanto, é responsabilidade parental, orientar os infantis em processo de formação e de amadurecimento. ${ }^{13}$

A infância é um período em que as experiências são determinantes para o desenvolvimento posterior.
É crucial que a criança experiêncie uma ampla gama de emoções e frustrações, para que aprenda a lidar com ambas posteriormente. ${ }^{6}$ Os arranjos e as configurações familiares e conjugais são cada vez mais diversos e as vinculações afetivas tendem a ser pouco duradouras, corroborando as formações vinculares à marca da instabilidade, resultando na terceirização de cuidados e isolamento. ${ }^{14}$

A teoria freudiana pressupõe adultos que imponham limites, que norteiem ordens e padrões a serem seguidos e em casos de transgressões ou infrações, imponham consequências, visto que os humanos são impossibilitados de orientarem-se, por seus próprios sentimentos, no que tange a uma diferenciação entre bem e mal, necessitando de motivos para submeter-se a uma influência exterior a ele. São descritos em termos de dependência absoluta em relação a um outro. ${ }^{3}$

Educação qualificada é aquela que estimula a criança a transpor limites, sejam aqueles próprios de sua idade, para se tornar um adulto, sejam aqueles de seu desempenho, para aperfeiçoá-los e dar o melhor de si. Assim, a educação não deve restringir-se aos ensinamentos de múltiplas regras, a conter e a impor limites. Essa transposição significa a superação de si mesmo e não a comedição do mundo capitalista, que valoriza a superação do outro e estimula o egoísmo. ${ }^{3}$

\section{Empoderamento dos pais sob a estruturação relacional vincular}

A família é o primeiro agrupamento e o mais próximo dentro da unidade da personalidade da criança, seguida pelos grupos escolares e pela sociedade. Para Winnicott (1966/1999a), é fundamental um olhar para os estados de desenvolvimento e crescimento da criança desde a sua concepção e em sua relação com o ambiente, logo após o nascimento. Cita a impossibilidade de entendimento de atitudes na relação vincular pais-filhos, sem que se considere o significado de cada criança em termos de fantasia subjetiva de seus pais. ${ }^{15}$

O papel dos pais é o de representar figuras de autoridade, o que não significa que desempenhem apenas funções punitivas. ${ }^{16}$ A função parental associa-se ao equilíbrio satisfatório entre o investimento narcísico e o investimento objetal nos filhos; esta visão estabelece uma relação entre a parentalidade e o narcisismo. ${ }^{17}$

A psicanálise mostra que o amor e a ternura permitem à criança superar os seus fracassos de modo que esta necessite dos pais para estruturar, tanto sua inteligência, como sua afetividade. ${ }^{18}$ Winnicott examinou o crescimento em termos da dependência rumo à independência da criança, entendendo que a maturidade está ligada a sua relação com o meio. A independência nunca chega a ser absoluta; isso porque, o ser humano, naturalmente, tende a não se isolar de seu meio, mas ambos se tornam interdependentes. ${ }^{19}$

Anna Freud estimula e amplia a compreensão de cuidado, associando às relações complexas entre a criança e os adultos que a educam. O papel do cuidador amplia-se ao equilibrar as exigências entre os extremos do consentimento das satisfações do indivíduo e a proibição da manifestação da pulsão. ${ }^{20}$

Uma criança em desenvolvimento é capaz de realizar internamente sua integração, o que acaba por exercer também um efeito integrativo sobre o ambiente externo imediato, contribuindo para a situação familiar. 
Assim, os pais devem apresentar condições de colaborar emocionalmente para manter o lar numa atmosfera saudável; muitas famílias permanecem intactas enquanto as crianças têm um bom desenvolvimento, mas são incapazes de suportar a presença de uma criança doente, já que, simultaneamente, os pais precisam dos filhos para desenvolver seus vínculos parentais e familiares. ${ }^{19}$

Neste sentido, o grupo familiar, termo que remete à figura dos pais, irmãos, inter-relacionamentos e demais relações diretivas à criança, exerce uma influência significativa no desenvolvimento vincular infantil. Em termos socioculturais, a configuração familiar vem sendo submetida a profundas transformações reais, principalmente no que tange à sucessão de gerações, fato que implica em repercussões significativas na formação das identidades individual, grupal e social. ${ }^{21}$

Algumas das influências culturais e sociais que atuam diretamente neste contexto são uma nova significação de família, com valores, expectativas e papeis novos; a emancipação da mulher, que exige uma conciliação entre maternagem e atividades profissionais; uma maior participação econômica doméstica e nos cuidados iniciais com os filhos; os avós que não dispõem de muito tempo para uma participação mais ativa junto aos netos, um número cada vez maior de mães adolescentes e solteiras, bem como de separações e novas constituições familiares. Além disso, o aumento notório do consumismo, a influência da mídia, na formação de valores ideológicos e a crescente angústia de ordem econômica, política e relativa a violência urbana influenciam na constituição da família. ${ }^{21}$

A família é um campo dinâmico no qual emergem conteúdos conscientes e inconscientes, sendo que, desde o nascimento, a criança sofre passivamente influências de seus cuidadores, porém, é tida como um poderoso agente ativo de modificações na estrutura totalitária da família. Não podemos deixar de citar aqui, a atuação dos aspectos transgeracionais, isto é, a interferência que cada um dos genitores mantém internalizada de suas famílias de origem, com suas respectivas cargas de valores, estereótipos e conflitos. Isto culmina em uma impetuosa tendência em que conflitos mal resolvidos pelos pais da criança, com seus genitores interiorizados, refletem na dinâmica da família. ${ }^{21}$

A pressão que a sociedade exerce sobre o indivíduo, desde sua infância, por meio da educação, faz com que a criança se conforme a uma realidade. A finalidade da educação é a instauração do princípio de realidade, ou seja, é permitir ao indivíduo a passagem para um universo simbólico, que faz referência a uma lei, neste caso, a lei da castração. O acesso ao mundo simbólico se dá por intermédio da linguagem; é pela mediação da palavra, à qual, desde sempre a criança encontra-se submetida, que é possível a simbolização das relações afetivas. ${ }^{20}$

É essa condição de ser submetido à linguagem que diferencia o homem dos outros animais e que permite a constituição de sua subjetividade. A psicanálise, ao designar a linguagem como marca do ser humano, aproxima-se às questões da educação, essencialmente quando trata da importância de atribuir significado àquilo que a criança diz, bem como ao que é dito a ela. ${ }^{20}$

Faz-se importante, nesse contexto, o acesso da criança a uma educação afetiva que lhe permita desen- volver uma sensibilidade relacional com os outros, de modo a acessar suas capacidades físicas e intelectuais, pois qualquer influência que alcance o grupo familiar integra o perfil caracterológico familiar que, inclusive, são variáveis de família para família. ${ }^{21}$

Uma família necessita de aspectos fundamentais, tais como hierarquização na distribuição de papeis, lugares e tarefas, com a conservação de um clima de liberdade e respeito recíproco entre os membros. Estes aspectos repercutem na formação do psiquismo do filho, fator que justifica a necessidade de empoderamento dos pais na educação e nos cuidados dos filhos, elencando um prolongamento nos lugares e funções cabíveis aos genitores, principalmente a função materna, desde o nascimento do filho. ${ }^{21}$

O processo de desenvolvimento e estruturação inicial do psiquismo infantil é marcado pela significativa influência da dependência, mais especificamente, relativa aos cuidados precoces com a criança. A dependência entre os seres existe, seja afetiva, intelectual ou espiritual. ${ }^{18}$

Visto isto, podemos nos ater à contribuição de Winnicott relativa à noção de independência, qualificando esta em três fases: dependência absoluta, dependência relativa e rumo à independência. $\mathrm{Na}$ dependência absoluta: a criança encontra-se em um período de total dependência, em que ela e o meio em que vive são um, e a mãe é quem vai permitir gradativamente o processo de maturação por meio da maternagem. Na dependência relativa, a criança se conscientiza de sua sujeição e tolera melhor as falhas de adaptação da mãe, tirando proveito delas para seu desenvolvimento, reconhece que os objetos e as pessoas fazem parte de sua realidade externa, ou seja, as falhas de adaptação da mãe são então ajustadas no desenvolvimento da criança, que sente a necessidade da mãe. O último estágio, rumo à independência, inicia-se quando à criança começa a lidar com perdas reais, ou seja, é necessário lidar com as perdas e frustrações, limites. ${ }^{22}$

Cabe equacionar aqui, a existência de três formas deletérias de educação: a severidade excessiva, a complacência excessiva e a incoerência nas atitudes dos educadores, inclusive com atitudes de indiferença pela criança. ${ }^{21}$ Impomos a nossos filhos muitos de nossos desejos totalmente e sem nenhum valor formativo moral. Os pais têm de educar e não agradar aos filhos, quanto mais esses mostram hostilidade com afeição aos pais, melhor é a sua saúde, significando, assim, que se libertaram dos laços incestuosos e da total dependência dos pais. ${ }^{18}$

A severidade e o caráter repressivo associam-se às funções do superego, instância psíquica representativa dos valores sociais e morais, os quais não devem ser vistos como simples repetições de características parentais. Tais características constituem produto do amestramento precoce das pulsões sexuais e agressivas consequentes de um superego colocado a serviço das exigências da cultura. ${ }^{12}$

A criança aprende muito através da imitação, portanto, ela se identifica com seus cuidadores, observando e reproduzindo suas atitudes, valores e comportamentos. ${ }^{4} \mathrm{Na}$ psicanálise, identificação é o termo empregado para designar o processo central pelo qual o sujeito se constitui e se transforma, assimilando ou se apropriando dos aspectos, atributos ou traços dos seres humanos que o cercam. ${ }^{12}$ 
A teoria freudiana compreende o psiquismo ao modo de um aparelho psíquico animado por pulsões, atribuindo à conflitiva edípica que consiste nas relações baseadas na tríade pai, mãe e criança e à sexualidade, no aspecto psicodinâmico do desenvolvimento psicossexual, os eixos básicos da vida psíquica e, como consequência, dá à representação do pai um lugar na base da moral e da própria vida cultural. ${ }^{23}$

Em Psicanálise, quando a criança supera sua conflitiva edípica, ou seja, quando a criança conscientiza-se de seus laços e afetos inter-relacionais com seus pais e reconhece estar excluída da relação entre o casal parental, mas incluída na relação familiar, tríade mãe-pai-criança, e tem possibilidade de acesso a um destino para suas angústias associadas, esta conflitiva propicia, por meio da interiorização de seus pais, de modo que, a criança identifica-se com os pais internalizando suas proibições e interdições. ${ }^{24}$

A disciplina de uma criança é responsabilidade de seus pais, quando uma criança consegue criar uma consciência moral, que envolva um conjunto de valores que permitam a distinção entre bem e mal, substituindo o controle externo pelo autocontrole, ela conseguiu chegar ao processo de internalização. Disciplina associa-se, ou à afirmação do poder, ou ao respeito à criança a primeira baseia-se em processos punitivos e a segunda em uma postura receptiva e encorajadora de autonomia. ${ }^{25}$

A disciplina objetiva propiciar auto governabilidade e autocontrole. A criança pode opinar sobre o que estiver em questão, mas quem decide as regras são seus educadores, devendo cumpri-las, estando de acordo ou não. As regras objetivas tendem a tornar a vida cotidiana facilitada. Em geral, a criança resiste ao controle, mas necessita dele e não continuará protestando se compreender que os pais não cederão e não farão exceções. ${ }^{26}$

Sem disciplina, o desenvolvimento moral fica impossibilitado, ou seja, a meta dos pais de ensinar a criança a se comportar caso alguém esteja olhando ou não, conforme asseguram à criança que ela terá consequências resultantes de seu mau comportamento. Os pais podem apresentar a consequência de uma maneira que assegure seu poder sobre a criança. Quando os pais ensinam os filhos a obedeceram às regras por questão de justiça e não de poder, possibilitam que seus filhos acessem a via do respeito da lei, assim, quando os pais não estivem mais no papel representacional de poder, os filhos estarão aptos a respeitarem os aspectos morais. ${ }^{27}$

O respeito que uma criança mantém por seus pais está na proporção direta do respeito que ela destinará às demais instâncias relacionais, legais e sociais. Há pais que impedem seus filhos de experimentar consequências decorrentes de seus atos. Desta forma, a criança perde o valor educativo da experiência e não tem acesso a noções de independência. ${ }^{26}$

As crianças necessitam desenvolver uma consciência moral, no sentido da compreensão de que as regras permanecem as mesmas porque elas têm uma importância singular, de modo que a meta dos pais é auxiliar as crianças no processo de utilização de seus recursos e a encontrarem sua própria motivação, visando a internalização de um código moral compartilhado. Uma criança deve ter ciência de que cometer erros é uma característica humana, porém estes resultam em consequências. ${ }^{27}$

A autoridade quando internalizada, possibilita o prolongamento da severidade da autoridade exterior; pais que falharem nesta educação moral, terão filhos apenas guiados pelos próprios desejos. É inerente ao ser humano a não realização da felicidade total, plena, pois o indivíduo tem de se deparar com sua própria finitude, sua limitação, suas mazelas e aprender a lidar com estas questões. A tarefa da educação é fazer a criança controlar seus instintos, pois se a criança colocasse em prática todos os seus impulsos sem restrições, a vida seria impossível para os pais e para as próprias crianças, pois sofreriam grande prejuízo, exteriorizado, em parte, nos anos subsequentes. A educação deve inibir, proibir e suprimir, mas, para isso, é importante dar à criança a quantidade exata de amor e, ao mesmo tempo, deve-se manter um grau eficaz de autoridade. ${ }^{28}$

Assim, torna-se viável a possibilidade de que a criança ao ampliar suas relações sociais, principalmente com sua entrada na escola, transfira para a figura do professor o respeito e a veneração antes dirigidos ao grupo familiar, de maneira a tratá-lo como se fosse seus pais, de modo que a transferência aconteça de forma natural na relação educador-educando, assim como nas outras relações humanas. ${ }^{20}$

\section{CONSIDERACÕ̃ES FINAIS}

O desenvolvimento infantil saudável encontra-se diretamente relacionado à vinculação satisfatória nas relações familiares. A procura por profissionais que atendem a demanda de pais e cuidadores está cada vez maior e a psicanálise, por intermédio de suas contribuições teóricas e técnicas, contemporâneas e ortodoxas, pode auxiliar no processo relacional e vincular das famílias, possibilitando o acesso a um ambiente familiar favorável ao desenvolvimento e provedor de saúde das crianças que nele vivem.

Pode-se observar a existência de uma relação entre educação e saúde, principalmente no que tange aos cuidados iniciais e desenvolvimentais destinados às crianças, oriundos dos pais ou cuidadores. O empoderamento nos cuidados dos filhos, nos processos educacionais, disciplinares e vinculares faz-se necessário e indispensável, pois possibilita a promoção da saúde ao desenvolver aspectos relativos à empatia, autoestima e consciência moral e ética.

Os pais tornam-se empoderados quando, diante de um erro dos filhos, os auxiliam a introjetar a instância da disciplina, visto que, a educação não é um discurso, e sim um modo de ser que inspira à criança confiança em si própria, que lhe dá segurança de que é sempre amada, mesmo sendo, às vezes, repreendida

Sugere-se o desenvolvimento de pesquisas empíricas sobre os fatores que contribuem ao empoderamento dos pais, que amparem e suportem as ações de promoção da saúde da criança e do adolescente, face às novas demandas socioculturais que influem e modificam a estruturação familiar grupal.

\section{REFERÊNCIAS}

1. Horochovski RR, Meirelles, G. Problematizando o conceito de 
empoderamento. Seminário Nacional Movimentos Sociais, Participação e Democracia 2007;2:485-506.

2. Andrade HF, Mendes R. Profissionais avaliam ações de promoção de saúde em São Paulo. Almanaque Dant. 2007. Junho.

3. La Taille, Y. Limites: Três Dimensões Educaçionais. São Paulo: Ática, 1998. 151p.

4. Vitorello, MA. Família contemporânea e as funções parentais: há nela um ato amor? Psicol Educ 2011;32:7-24.

5. Barbosa, PV, Wagner, A. A construção e o reconhecimento das regras familiares: a perspectiva dos adolescentes. Psicol Estud, Maringá 2014;19(2):235-45. doi: 10.1590/1413737222060007.

6. Weber LND, Viezzer AP, Brandenburg OJ. O uso de palmadas e surras como prática educativa. Psicol Estud 2004;9(2):22737. doi: 10.1590/S1413-294X2004000200004.

7. Toni CGS, Hecaveí VA. Relações entre práticas educativas parentais e rendimento acadêmico em crianças. Psico USF 2014;19(3):511-21. doi: 10.1590/1413-82712014019003013

8. Marraccini EM. Sobre limites em psicanálise. Rev Latinoam Psicopat Fund 2012;15(3):609-11. doi: 10.1590/S141547142012000300012.

9. Abrão JLF. As origens da psicanálise de crianças no Brasil: entre a educação e a medicina. Psicol Estud 2009;14(3):42332. doi: 10.1590/S1413-7372200900030000

10. La Taille Y. Moral e ética: uma leitura psicológica. Psicol Teor Pesqui 2010;26(n.esp):105-14. doi: 10.1590/S0102 37722010000500009.

11. La Taille, Y. Moral e ética: dimensões intelectuais e afetivas. Porto alegre: Artmed Editora, 2007. 192p.

12. Roudinesco E. Dicionário de psicanálise. Rio de Janeiro: Zahar. 1998. 875p.

13. La Taille, Y. Desenvolvimento humano: contribuições da psicologia moral. Psicologia USP 2007;18(1):11-36. doi: 10.1590/S0103-65642007000100002.

14. Quagliatto HSM, Cunha MF, Chaves LS. Intervenção psicanalítica conjunta pais-filhos: fundamentos teórico/ clínicos. Estilos Clín 2012;17(2):228-41. doi: 141571282012000200004.

15. Winnicott, DW. A família e o desenvolvimento individual $\left(2^{\mathrm{a}}\right.$ edição). São Paulo: Martins fontes, $2^{\mathrm{a}}$ edição, 2001.

16. LIMA, R. O declínio da autoridade: efeitos na família e na escola. Rev Espaço Acadêmico 2009;9(102):111-19.

17. Veludo $\mathrm{CMB}$, Viana TC. Parentalidade e o desenvolvimento psíquico na criança. Paidéia (Ribeirão Preto) 2012;22(51):1118. doi: 10.1590/S0103-863X2012000100013

18. Dolto FS. As etapas decisivas da infância. São Paulo: Martins Fontes, 1999.

19. Winnicott DW. O ambiente e os processos de maturação: estudos sobre a teoria do desenvolvimento emocional. São Paulo: Artes médicas, 1983.

20. Pedroza RLS. Psicanálise e educação: análise das práticas pedagógicas e formação do professor. Psicol Educ 2010;(30):81-96. doi: 1414-69752010000100007.

21. Zimerman DE. Fundamentos psicanalíticos: teoria, técnica, clínica-uma abordagem didática. Porto Alegre: Artmed Editora, 1999. 478p.

22. Nasio JD. Introdução às obras de Freud, Ferenczi, Groddeck, Klein, Winnicott, Dolto, Lacan. Rio de Janeiro: Zahar, 1995. 305p.

23. Rosa CD. O papel do pai no processo de amadurecimento em Winnicott. Nat hum 2009;11(2):55-96. doi: 151724302009000200003.

24. Zimerman DE. Vocabulário contemporâneo de psicanálise. Porto Alegre: Artmed Editora, 2001. 459p.

25. Cória Sabini MA. Fundamentos de psicologia educacional. Rio de Janeiro: Atica, 1991. 798p.

26. Van Pelt N. Filhos: educando com sucesso. São Paulo: Casa Publicadora Brasileira, 1998.

27. Brazelton TB, Sparrow JD. Disciplina: o método Brazelton. Porto Alegre: Artmed, 2005. 93p.

28. Freud S. O mal-estar na civilização. São Paulo: Editora Companhia das Letras, 2011.

Como citar: FERREIRA, Sérgio Murilo et al. O empoderamento dos pais na educação e nos cuidados dos filhos: contribuições teóricas. Cinergis, Santa Cruz do Sul, v. 17, n. 3, set. 2016. ISSN 2177-4005. Disponível em: <https://online.unisc.br/seer/ index.php/cinergis/article/view/8060>. Acesso em: 11 out. 2016. doi:http://dx.doi.org/10.17058/cinergis.v17i3.8060. 